\title{
COMMENTARY
}

\section{SDGs: The Need for Vital Registration and Accurate Record Keeping}

\author{
Paul Feyi-Waboso \\ Professor, Department of Obstetrics and Gynaecology, Dean of Clinical Medicine, Abia State University, PMB 2000, Nigeria.
}

*For Correspondence: E-mail:wabosop@gmail.com; Phone: +2348033093178

Sixteen years ago, the target of a $75 \%$ reduction in the global maternal mortality ratio between 1990 and 2015 was specified as an indicator for the Millennium Development Goal (MDG) 5 to improve maternal health ${ }^{1}$. Analysis by the UN Maternal Mortality Estimation Inter-Agency Group reports an estimated global maternal mortality ratio of 216 per 100,000 live births $(80 \%$ Uncertainty Interval 207-249) in 2015. Despite a marked reduction in many countries between 1990 and 2015, the maternal mortality ratio is still alarmingly high in many places, notably in subSaharan Africa, where many countries still have more than 500 maternal deaths per 100, 000 live births ${ }^{2}$.

The 1990 and 2015 Maternal Mortality Ratio estimates for Nigeria have been quoted as $1,350(893-1820 \mathrm{UI})$ and 814(596-1180UI) respectively $^{3}$. However, the 2013 Nigeria Demographic and Health Survey reported an estimate of 576 (Confidence Interval 500-562). Critics argue that these estimates are inconsistent and that Nigeria has failed to meet the MDG 5 target MMR of 300/100,000 live births calculated by 'Countdown to $2015^{\prime 4}$. As well as marking the end of the MDG era, 2015 also saw a new set of development targets proposed in the Sustainable Development Goals (SDGs), which are to be achieved over the next 15 years ${ }^{5}$. The 2030 SDG target 3.1 is to reduce the global maternal mortality ratio to less than 70 per 100 , 000 live births, with no country exceeding twice that level.

One major reason why some countries made little or no progress towards achieving MDG 5 is the lack of reliable data on which to measure progress and initiate action. Unfortunately, countries with the highest burden of maternal morbidity and mortality have the least reliable data on such health indicators ${ }^{6}$. In most low-income countries, due to lack of complete and accurate civil registration systems, MMR estimates are based on data from a variety of sources including censuses, household surveys, reproductive age mortality surveys, and verbal autopsies ${ }^{7}$. For instance, in Nigeria, there are no population-based data on maternal deaths and the vital registration system is currently unable to provide reliable estimates. The country relies on estimates derived from statistical modelling by international agencies, which are often insufficient to assess the quality of care, monitor trends or determine national health system priorities ${ }^{6}$. Maternal mortality estimation is difficult. Household surveys and hospital studies have data quality problems and are not even available in many parts of Nigeria. National censuses are few and far between and they only give retrospective data over a relatively long time period.

It is likely that there are more maternal deaths than reported. This is supported by a 1991 WHO statement that data used in most analyses were obtained from hospital records ${ }^{8}$. In Nigeria, only $35 \%$ of women deliver in hospital ${ }^{9}$. It can, therefore, be argued that these hospital records may show only the incidence of maternal deaths that occurred in hospitals. It is suggested that many women die at home and their deaths are not reported. The Demographic and Health Surveys Program $^{10}$ uses the sisterhood method for Maternal Mortality estimations. This household questionnaire based method remains the major source of empirical data on maternal mortality in low- income countries, although it also presents notable limitations. All deaths with unknown status about pregnancy are in fact classified as non-maternal and almost half of the surveys have more than $10 \%$ missing responses for this variable. This assumption introduces a significant underestimation bias that requires statistical adjustment. More importantly, sisterhood methods 
measure the situation approximately 12 years retrospectively. The surveys are infrequent, the last one having been done in 2013. The next survey is not scheduled until 2018. It gives retrospective data over a long time period and does not account for intra- country variations.

The Nigerian Multiple Indicator Cluster Survey (MICS) ${ }^{11}$ estimated the Nigerian Maternal Mortality Ratio as 1100/100,000 in 2005 whereas the National Demographic Health Survey ${ }^{12}$ reported Maternal Mortality Ratio was $545 / 100,000$ live births in 2008 and 576/100,000 in 2013. It is very unlikely that these differences between the two surveys were accurate and very probably arose from differences in methodology. In the few parts of Nigeria, where verbal autopsies are employed as an instrument for data collection, the challenge is that critical information on victims required to produce a comprehensive report is often omitted ${ }^{13}$.

\section{Implications of lack of credible data}

The absence of statistics has immediate implications for policy makers. Without reliable information, government officials who allocate resources for health budgets are essentially working in the dark. The low quality of statistics results in adverse outcomes, such as underfunding and poor monitoring of many development programmes ${ }^{14}$. Lack of credible data also affects other forms of public statistics vital to Nigeria's survival, development and economy. For example, national and international trade and finance will be inefficient. Regarding water supply, the analysis of many household surveys produces a single national estimate of access to safe water in rural areas, but does not show how it varies between districts ${ }^{15}$. In distribution of farm subsidies for agriculture, a database can reveal how a small group of wealthy farmers can capture the vast majority of subsidy funds. Absence of quality data on maternal mortality for low- income countries and the use of diverse research methods in estimating the levels of maternal mortality make adequate monitoring of the trends and comparisons across countries difficult and complicated $^{17}$. The absolute number of maternal deaths emphasizes the magnitude rather than the risk of maternal death within a given population.
The number of maternal deaths is a self-evident measure that gives a clear indication of the public health impact of maternal mortality which could serve as reference points for health advocates and policy makers ${ }^{18}$. The Commission on Information and Accountability for Women's and Children's Health $^{19}$ established in 2011 "to determine the most effective international institutional arrangements for global reporting, oversight and accountability on women's and children's health," stated that "by 2015, all countries (are expected to) have taken significant steps to establish a system for registration of births, deaths and causes of death and have well-functioning health information systems that combine data from facilities, administrative sources and surveys, ${ }^{, 20}$. This has failed to be actualised in many lowincome countries.

A 2014 UN report "A World that Counts" 21 suggests mobilizing a data revolution for sustainable development. The UN SecretaryGeneral's High-level Panel of Eminent Persons report $^{22}$ has called for positioning Civil Registration Vital Statistics(CRVS) as part of the data revolution. There's a reason for the saying "What counts gets counted and what's counted counts". Measurement matters, and with an agenda as big as the SDGs the indicators become that more crucial.

\section{Limitations of the MDG 5: implementation and enforcement}

Availability and reliability of data have been the most often reported challenges with regards to implementation of the MDGs and subsequently in the interpretation of progress reports ${ }^{23,24}$. Attaran ${ }^{25}$ explained further that the health-related baselines from 1990 were often based on unreliable household surveys with no birth and death registries, health records or health statistics. This applies to Nigeria where data is inaccurate on numbers of maternal deaths on a continuous basis as CRVS is still not in place. The Millennium Development Goals Report released by the United Nations in 2015 stated "data gaps remain... poor data quality, lack of timely data and unavailability of disaggregated data... are among the major challenges [to MDG monitoring]. In short, poor (or non-existent) data will keep us from 
quantifying the impact of many MDGs". It has also been argued that the MDG 5 Goal was unfair to Africa right from inception and doomed to failure. "Africa was said to be failing the goal of reducing maternal mortality by two-thirds, but there were no reliable data on maternal mortality trends "even when there are no reliable data, Africa was still said to be failing ${ }^{26}$.

\section{Historical perspective of registration systems and vital statistics in Nigeria}

Ayeni ${ }^{27}$ in 1971 and $\mathrm{Umoh}^{28}$ in 1972 reported that there was a system of vital registration in operation in Lagos City and Katsina province. Rehan and Tafida ${ }^{29,30}$ also made use of vital statistics to publish sentinel articles on certain aspects of perinatal biodata in Katsina because they could examine records of a reliable system of birth and death registration which had been operating for 25 years $^{31}$. How did they do it? In Katsina province, the local religious leaders, the 'Imams', perform all weddings, burials and naming ceremonies. They were directed to keep records of all these events in their respective villages. They make returns of these events to the District Head (traditional ruler) every month, who transcribes the crude data and sends a consolidated return to local government authorities at provincial headquarters ${ }^{31}$. It can be seen that some measure of success was achieved by committed individuals. Progress has lost momentum. This could have formed a template for civil registration and the collection of health related information in rural areas. Unfortunately, Nigerians have allowed themselves to fall back on the use of estimates in computing maternal and perinatal statistics ${ }^{32}$.

The reasons why the system in the Northern part of the country were not taken to scale at national level can be argued to be multifactorial. There has been a lack of political will and lack of funding of the primary health care system i.e. the Community level. There has been a disconnect between the Primary, Secondary and Tertiary health tiers in terms of data generation due to lack of a concerted effort. Official data can only be obtained from hospital service records where these exist, but in many parts of the country, only few women have access to health facilities for deliveries. Therefore it has become necessary to conduct surveys to collect data.

\section{Present situation in Nigeria towards data generation}

The Abiye (Safe Motherhood) project in Ondo State, Nigeria was started in 2009. Underpinning the program has been consistent emphasis on data collection. It began with extensive baseline surveys at the community level. A Law has been passed mandating reporting of maternal death irrespective of where death occurred. The importance of having solid data and the need for accurate record keeping and reporting has been emphasized. Mobile phones and "smart cards" that store a woman's basic information and health record greatly facilitate data collection and analysis across facilities. A maternal audit system, the Confidential Enquiry into Maternal Deaths in Ondo State (CEMDOS) is operational and three annual reports (2012-2015) have been published ${ }^{33}$. This has laid the foundation for accurate measurement of maternal mortality rate in Ondo State. It provides a positive preliminary model of how data collection, technology and innovation, efficient use of resources, and mechanisms of accountability-backed up by sustained political will, can come together in a comprehensive strategy that is yielding results ${ }^{34}$ As a promising, home -grown "effort to improve maternal health outcomes, the program has been called "a role model and a benchmark for the African continent in tackling infant and maternal mortality ratio ${ }^{35}$.

Maternal Death Reviews (MDRs) are operating and the Women's Health Action Research Centre (WHARC) have been a champion of the initial efforts in Nigeriaare involved with maternal death audits. MDSR are in the process of being instituted in many Nigerian states with great contributions by the Society of Obstetricians and Gynaecologists of Nigeria (SOGON). The concept is based on the Beyond the numbers Guide $(2004)^{36}$ in which a key statement was "the information that countries need to address maternal mortality goes beyond just measuring the level of the problem". However, twelve years later 
Nigeria still does not have accurate data on numbers of maternal deaths for monitoring and evaluation. Without a baseline, we cannot measure accurately.

\section{The SDGs: Power of baseline data-What's our Baseline?}

Some critics have argued that the SDGs are not measurable. This is a problem, they say, because for goals to be meaningful, you need a baseline to understand where things are starting and at least one other data point to assess progress ${ }^{37}$. How important are baselines? We need to start somewhere. In order to track progress towards the MDGs, the UN's website on the MDG indicators provided information about how many data points each indicator have. Two data points is the bare minimum to know if there has been progress towards an indicator. Without at least two data points, we don't know whether things are improving, stagnating, or deteriorating. The MDG database reports that for maternal mortality ratios, only $14 \%$ of low-income countries have two observations. How confident can we be that there has been progress towards the MDGs with so little information?

\section{The way forward: Data collection and management}

There should be a paradigm shift towards counting maternal deaths throughout Nigeria as a baseline. In agreement with Harrison ${ }^{38}$ we should start from reality, which means actual counts of births and deaths on a continuous basis and in a continuous manner, not ad-hoc estimates of population data. The use of estimates is a poor substitute for compulsory civil registration. The three tiers of health care must go back to basics which is existence of data tools. There must be a man power organization created, responsible for data generation and transmission. The chief executives of state agencies and institutions in the health sector should be made to come together to serve as a data generation/user working group. Together they will have the imperative of ensuring that baseline data from every sector and the three tiers of government will be made to flow together on a continuous basis. After collection, it is transmitted to the Ministry of Health and a Health Management system will be discussed and ensured. On this basis we can expect a unified approach to data generation.

Since the majority of births in Nigeria occur in the rural areas, data should be collected for a baseline at the community level in all Nigerian States using the Ondo State experiment as a template. Community health workers can record all maternal deaths by Rapid SMS with mobile phones. This data can be updated on the RapidSMS dashboard which is accessible over the web. Although it is easier to register births than deaths, RapidSMS is already being used in most states of Nigeria for registration of births and also for registration of pregnant women, so accurate recording of deaths can also be achieved. Data can also be collected through face to face interviews and online. All the data can be aggregated into a single national database open to all and the data can be disaggregated, for example by age and level of education ${ }^{21}$. We can then define maternal deaths. If we have a baseline we have an accurate starting point and for the SDG goal on Maternal Health to be meaningful, at least one other data point to assess progress should be measured for evaluation. If we do not have a baseline, we cannot proceed to measurement and evaluation. Nigeria will then have an ongoing nation-wide data collection system of Civil Registration and Vital Statistics. Political will is imperative to drive the process of transforming maternal health care in Nigeria $^{39}$ and will be required to scale up the current programme in Ondo State to the national level.

\section{Conclusion}

For the next 15 years, we must learn from our MDG experiences to meet the SDGs incorporating lessons learned from the past 15 years into plans and programs at the local and national levels. A key MDG takeaway must be that timely, accurate, and shareable data are necessary to ensure effective, innovative, and concerted interventions. In light of the "Data Revolution" movement that seeks to remedy data gaps, particular emphasis must be placed on Data baselines: without accurate knowledge of the current state-of-play, creating achievable goals let 
alone monitoring and evaluation metrics becomes impossible.

\section{Declaration}

The author conceived the article and prepared the manuscript.

\section{References}

1. UN General Assembly. United Nations Millennium Declaration, Resolution Adopted by the General Assembly. Sept 18 2000. http://www.un.org/mille nnium/declaration.html.

2. Alkema L, Chou D, Hogan D, Zhang S, Moller AB, Gemmill A, Ma Fat D, Boerma T Temmerman M, Mathers C, Say L on behalf of the United Nations Maternal Mortality Estimation InterAgency Group collaborators and technical advisory group. Global, regional, and national levels and trends in maternal mortality between 1990 and 2015, with scenario-based projections to2030: a systematic analysis by the UN Maternal Mortality Estimation Inter- Agency Group. Lancet 2016; 387: 462-74.

3. Maternal mortality in 1990-2015 WHO, UNICEF, UNFPA, World Bank Group, and United Nations Population Division Maternal Mortality Estimation Inter-Agency Group NIGERIA.

4. Countdown to 2015.Maternal, Newborn \& Child Survival.Fulfilling thrHealth Agenda for Women and Children. The 2014 Report.

5. UN General Assembly. Transforming our world: the 2030 agenda for sustainabledevelopment, resolution adopted by the General Assembly Sept 25, 2015.A/ RES/70/1.http://www.un.org/ga/search/vie w_doc.

6. Oladapo OT, Adetoro OO, Ekele BA, Chama C, Etuk SJ, Aboyeji AP, Onah HE, Abasiattai AM, Adamu AN, Adegbola O, Adeniran AS, Aimakhu CO, Akinsanya $\mathrm{O}$, Aliyu LD, Ande AB, Ashimi A, Bwala M, Fabamwo A, Geidam AD, Ikechebelu JI, Imaralu JO, Kuti O, Nwachukwu D,Omo-Aghoja L, Tunau K, Tukur J, Umeora OUJ, Umezulike AC, Dada OA, Tuncalp Ö.

7. Vogel JP, Gülmezoglu A. Nigeria Near-miss and Maternal Death Surveillance Network. When getting there is not enough: a nationwide crosssectional study of 998 maternal deaths and 1451 near-misses in public tertiary hospitals in a lowincome country. BJOG 2016;123:928-938.

8. Ferreira MCC, de Figueiredo RP, Laurenti R, Viana MB,Falcao AAA, Riberio CMC , Camara JEV.The importance of the investigation of deaths and the committee's action in the diagnosis of maternal morbi-mortality. J Epidemiol Community Health 2011;65(1):A146-7.

9. World Health Organization. (1992). International statistical classification of diseases and related health problems, tenth revision. Geneva: WHO.
10. World Bank. (2003). The millennium development goals for health: Rising to the challenges (draft). Washington: World Bank.

11. Saifuddin A, Li Q, Scrafford C, Pullum TW 2014. An assessmentof DHS Maternal Mortality Data and Estimates DHS Methodological Reports No. 13. Rockwille,Maryland, USA: ICF International.

12. At a glance Nigeria:MICS 2005 Available at:http:// www.unicef.org/statistics/index_countrystatis.html.

13. National Population Commission (NPC)[Nigeria] and ICF Macro.2009.Nigeria Demographic Survey 2008.Abuja,Nigeria:National Population and ICF Macro.

14. Oyeneyin OL. Maternal Death Review - The Ondo State Experience, SOGON Annual Conference, Abuja,November 2015.

15. Okonjo-Iweala $\mathrm{N}$, Osafo-Kwaako $\mathrm{P}$. Improving health statistics in Africa .Lancet 2007 ;370: 1527-1528

16. AWorld that Counts. Mobilising the Data Revolution for asustainable Development .A United Nations report repared at the request of the United Nations Secretary-General, by the Independent Expert Advisory Group on a Data Revolution for Sustainable Development in November 2014

17. Hakkert R. Country estimates for maternal mortality: An alternative model. Statistics in Medicine 2001; 20: $3505-3524$.

18. Hill K, Abouzahr C, Wardlaw T. Estimates of maternal mortality 1995. Bulletin of the World Health Organisation .2001;79(3): 182-93.

19. Fortney JA. The importance of family planning in reducing maternal mortality. Stud Fam Plann 1987; 18:109-114.

20. WHO Commission on Information and Accountability for Women's and Children's Health. Keeping promises, measuring results. Geneva, World Health Organization, 2011.

21. WHO independent Expert Review Group (iERG). Every woman every child: from commitments to action: The first report of the independent Expert Review Group (iERG) on Information and Accountability forWomen's and Children's Health. Geneva, World Health Organization, 2012.

22. A World that Counts. Mobilising the Data Revolution for asustainable Development .A United Nations report prepared at the request of the United Nations Secretary-General, by the Independent Expert Advisory Group on a Data Revolution for Sustainable Development in November 2014.

23. UN. A new global partnership: eradicate poverty and transform economies through sustainable development. The report of the high-level panel of eminent persons on the post-2015 development agenda. May 30, 2013. http://www.un.org/sg/ management/pdf/HLP_P2015_Report.pdf.

24. Dar OA, Khan MS.Millennium development goals and the water target: Details, definitions and debate. Tropical Medicine \& International Health 2011; 16: 540-44.

25. Sachs JD. From millennium development goals to 
sustainable development goals. Lancet 2012; 379: 2206-11

26. Attaran A. An immeasurable crisis? A criticism of the millennium development goals and why they cannot be measured. Plos Medicine 2005; 2: 955-61.

27. Easterley W.How the Millennium Development Goals are Unfair to Africa . World Development 2009; 37( 1): $26-35$.

28. Ayeni 0. Guidelines for the establishment of vital statistics registration system in Nigeria. Niger Med J 1971;1:214-19.

29. Umoh OE. Demographic statistics in Nigeria. In Population Growth and Economic Development in Africa (Ominde SH. \& Ejiogu CN, Eds), Heinemann. London 1972,21-25.

30. Rehan NE, Tafida DD. Birth weight of Hausa infants in northern Nigeria. $\mathrm{Br} \quad J$ Obstet Gynaecol 1979;86:433-49.

31. Rehan NE , Tafida DS. Multiple births in Hausa women. Br J Obstet Gynaecol 1980 ;87:9971004.

32. Rehan N. Sex Ratio of live born Hausa infants. BJOG $1982 ; 89: 136-141$

33. Harrison KA. Nigerian politics and safe motherhood. BJOG 2007;114:771-2.
34. Report on the Confidential Enquiry into Maternal Deaths in Ondo State(CEMDOS) by the Committee for CEMDOS,December 2015.Published by Ministry of Health,Ondo State.

35. Maternal Health in Nigeria. With Leadership ,Progress Is Possible. A Report of the Center for Strategic and International Studies. Global Health Policy Center. Cooke JG and Tahir F:1-16.

36. Sola Ogundipe 'World Bank seeks adoption of Ondo State's Abiye project as a model for Africa' Vanguard(Nigeria)July 19,2011.http://www.vanguar dngr.com.

37. Beyond the Numbers .Reviewing maternal deaths and complications to make pregnancy safer.World Health Organization, Geneva, 2004.

38. The SDGs - What's Your Baseline? Sep 1, $2015 \cdot$ Zach Christensen-Blog- Development Gateway, Solutions that Empower.

39. Harrison KA. The struggle to reduce High Maternal Mortality in Nigeria.Afr J Reprod Health 2009;13( 3):9-20.

40. Shiffman J and Okonofua FE. The state of political priority for safe motherhood in Nigeria. BJOG 2007; 114: $127-133$. 